\title{
MEDIUM AND LONG-TERM INFLUENCES OF TYPICAL PLANTATIONS ON SURFACE SOIL NUTRIENTS IN THE TEMPERATE ZONE OF MOUNT MENG, CHINA
}

\author{
GAO, Y. $\cdot^{1,2^{*}}-$ WANG, $\mathrm{Y}^{1}$ \\ ${ }^{1}$ Shandong Provincial Key Laboratory of Water and Soil Conservation and Environmental \\ Protection, College of Resources and Environment, Linyi University, Linyi 276005, China \\ (e-mail:wangyunsd@163.com) \\ ${ }^{2}$ Linyi Scientific Exploration Laboratory, Linyi 276037, China \\ *Corresponding author \\ e-mail: gaoyuan1182@tom.com,gaoy@lyu.edu.cn \\ (Received $31^{\text {st }}$ May 2018; accepted $2^{\text {nd }}$ Aug 2018)
}

\begin{abstract}
Very few studies are concerned with the medium and long-term soil nutrients of plantations, which often have inconsistent research results. This paper studied the characteristics of the surface soil nutrient changes in two types of plantations with different stand age: 30 years and 60 years. They are needle-leaved plantations (Pinus thunbergii plantation and Pinus densiflora plantation) and broad-leaved plantations (Quercus variabilis plantation). Research results showed: 1) When the stand age is 30 years, the content of organic matters and the nitrogen of the surface soil was presented as follows: Pinus thunbergii plantation>Quercus variabilis plantation>Pinus densiflora plantation, and the content of organic carbon, available phosphate and rapidly available potassium of the surface soil was presented as follows: Quercus variabilis plantation>Pinus thunbergii plantation>Pinus densiflora plantation. Significant differences were found in the content of active organic carbon in the surface soil. 2) When the stand age is 60 years, the content of organic matters, the total nitrogen and rapidly available potassium in the surface soil was presented as follows: Pinus densiflora plantation>Quercus variabilis plantation> Pinus thunbergii plantation and significant differences were found in the content of organic matters and total nitrogen of the surface soil. The content of active organic carbon in the surface soil was ranked as follows: Pinus thunbergii plantation>Pinus densiflora plantation>Quercus variabilis plantation. 3) Among the plantations with 60 -year stand age, the content of five nutrients all increased in the surface soil of the Pinus densiflora plantation, namely, organic matters, active organic carbon, total nitrogen, available phosphorus and rapidly available potassium. The content of organic matters, total nitrogen and available phosphorus significantly increased in the surface soil, but no significant differences were found in the surface soil nutrient content of Quercus variabilis plantation and Pinus thunbergii plantation.

Keywords: plantation, soil nutrient, organic matter, active organic carbon, total nitrogen, available phosphorus, available potassium
\end{abstract}

\section{Introduction}

At the Asia-Pacific Regional Conference on Forest Restoration on March 26, 2018, Peng Y. D., deputy director of the State Forestry Administration, pointed out that as of 2017, China's plantation forest area was $693,300 \mathrm{~km}^{2}$, ranking first in the world. Forest plantation is a major measure to recover the degraded ecosystem and conserve the ecosystem service functions (Togonidze and Akhalkatsi, 2015; Wei et al., 2017; Yin et al., 2018). In the forest ecosystem, the vegetation of plantations influences a lot of ecological processes above and below the ground, and plays a crucial role in maintaining the stability and diversification of the forest ecological system (Nilsson and Wardle, 2005). In the ecological restoration of the forest, the changes of soil nutrients have been a focus of the modern ecological research. Soil, an important component of 
the forest ecosystem, provides necessary nutrients for the growth and propagation of plants as well as serves as carriers to the multiple ecological processes in the ecosystem (Trumbore and Czimczik, 2008). The status of forest soil nutrients is influenced by factors like climate, soil types and vegetation types together (Roy et al., 2010; Schmidt et al., 2015; Hedwall et al., 2015). Soil nutrients are important quantitative indexes of soil fertility, and they are crucial to the species composition and structural changes of vegetation. Moreover, they directly influence the productivity level of the ecosystem (Xu et al., 2008; Schmidt et al., 2015). The forest succession and the compound afforestation pattern obviously influence the soil fertility (Rutigliano et al., 2004; Hedwall et al., 2015). Vegetation influences the characteristics and development of the soil because the changes accompanying the vegetation succession, plant litters and root exudates directly influence the quantity of the input soil nutrients (Jia et al., 2005). Different development stages of plantations are throughout the whole life cycle of the forest growth. Therefore, it is of great ecological significance to understand the soil fertility of different development stages and the fertilizer requirement characteristics of forests in the plantation management. It could provide the scientific basis for the operation and management of the local plantations and evaluate the ecological consequences of the introduced exotic tree species.

The existing experimental research shows that broad-leaved species could immobilize more nutrients than coniferous species in the restoration of the forest the stand age of which is less than 30 years (Laganière et al., 2010; Li et al., 2012; Nave et al., 2013). However, the research ignores the changes of the soil nutrient storage in the restoration of the forest the stand age of which is over 30 years (Wang et al., 2016). Coniferous species are more difficult to resolve than broad-leaved species. Theoretically, the former is higher than the latter in the quantity of the immobilized soil nutrients (Vesterdal et al., 2008; Wang et al., 2016). These research inconsistencies reflect that: the soil nutrient data of the medium and long term plantations (trees whose stand age is over 30 years) are required for the research, especially those plantations with over 50 years of stand age because of their scarcity and preciousness (Bai et al., 2008; Gao et al., 2013).

Mount Meng is located in the low hilly areas of the central-south Shandong Province of China, and it is one of the two major ecological reserves in Shandong. Meanwhile, it is also a typical representative of the rocky mountain areas in northern China as well as one of the earliest areas to develop plantations in China. Typical plantations are Pinus thunbergii (black pine) plantation, Pinus densiflora (red pine) plantation and Quercus variabilis (cork oak) plantation (Gao et al., 2009, 2011, 2013). According to different forest types, studies relevant to surface soil nutrients and their dynamics are conducted, which helps to understand the surface soil nutrient supply of the forest ecosystem. This study will explore the soil surface nutrient changes of needle plantations (Pinus thunbergii plantation and Pinus densiflora plantation) and broad-leaf plantations (Quercus variabilis plantation) in terms of the stand age: 30 years and 60 years. The presupposed scientific hypotheses of the study are as follows: 1) Litters of coniferous species are more difficult to resolve than those of broad-leaf species. If the stand age of plantations are the same, more surface soil nutrients should be accumulated, namely, needle plantations are higher than broad-leaf plantations in the content of soil surface nutrients when their stand age are both 60 years. 2) The content of soil surface nutrients of plantations increases progressively along with the time, namely, the 60-year plantations have more soil surface nutrients than the 30 -year plantations. 


\section{Materials and methods}

\section{Research sample plot}

The research was conducted in typical areas of Mount Meng. Located in the warm temperate zone of the southeastern hilly areas in Shandong Province, Mount Meng covers an area of 1,125 square kilometers, and its soil is the brown forest soil. The research selected Pinus thunbergii plantation, Pinus densiflora plantation and Quercus variabilis plantation with two types of stand age - 30a and 60a as research plots by investigating the community structure of wild plants and interviewing the technicians of the forest station in order to carry out the soil sampling. Forest in this area has been damaged by man-made for a long time. In 1949, only about $25 \mathrm{~km}^{2}$ of forest was left, the forest coverage rate was less than $2 \%$, and there were less than 300 plant species. The government has successively established 7 forest farms in Tashan, Wanshou Palace, Tianma, Mingguang Temple, Datun, Hailuo Temple and Tianbao Mountain to restore and reconstruct Mengshan vegetation from the 1950s to the 1980s.

\section{Research methods}

The sample plots were selected as follows: 12 sample plots of Pinus thunbergii plantation (6 sample plots with 30 years of stand age and 6 sample plots with 60 years of stand age), 12 sample plots of Pinus densiflora plantation (6 sample plots with 30 years of stand age and 6 sample plots with 60 years of stand age), and 16 sample plots of Quercus variabilis plantation (8 sample plots with 30 years of stand age and 8 sample plots with 60 years of stand age). The sampling area coordinates were $35^{\circ} 10^{\prime} \sim 36^{\circ} 00^{\prime} \mathrm{N}, 117^{\circ} 35^{\prime} \sim 118^{\circ} 20^{\prime} \mathrm{E}$. The plot spacing is more than $1 \mathrm{~km}$. There was no garbage in the plot, and the roots of the plant were dried when the soil sample was treated.

1 quadrat of $20 \mathrm{~m} \times 30 \mathrm{~m}$ was selected in each sample plot, and the five-point sampling method was used to drill 5 repeated soil samples. The diameter of the earth boring auger was $3.5 \mathrm{~cm}$ and the sampling depth was $10 \mathrm{~cm}$ (Wang et al., 2017). Then, the repeated soil samples were mixed into one soil sample and taken to the lab. Sampling was conducted in August, 2016, and the lab was responsible for the assay determination of organic matters, active organic carbon, total nitrogen, available phosphorus and rapidly available potassium of the soil samples. According to the LY/T1237-1999 standard for the organic matters of forest soil, the external heating method of potassium dichromate was used for measuring the organic matters of soil, and the potassium permanganate oxidation method was adopted for measuring the content of active organic matters. According to the LY/T 1228-2015 standard of nitrogen measurement for the forest soil, the Kjeldahl nitrogen method was used to measure the content of total nitrogen. According to the LY/T 1232-2015 standard of phosphorous measurement for the forest soil, the colorimetric method was used for measuring the phosphorous content. According to the LY/T 1234-2015 standard of potassium measurement for the forest soil, the atomic absorption spectrophotometer was used for the rapidly available potassium measurement.

\section{Statistical analysis}

The single factor statistical method was used to analyze the soil nutrient differences of the forest type, and $\mathrm{T}$ test was applied to measure the soil nutrient differences of the 
plantations with different stand age. SPSS 17.0 and Excel 2003 were used for the data analysis and table introduction.

\section{Results and analysis}

\section{Organic matters of surface soil}

In plantations with the same stand age but different forest types, the organic matter content was as follows: 1) when the stand age of plantations is 30 years, Pinus thunbergii plantations $\left(33.03 \pm 8.86 \mathrm{~g} \cdot \mathrm{kg}^{-1}\right)>$ Quercus variabilis plantation $(28.78 \pm$ $\left.5.33 \mathrm{~g} \cdot \mathrm{kg}^{-1}\right)>$ Pinus densiflora plantation $\left(24.40 \pm 11.26 \mathrm{~g} \cdot \mathrm{kg}^{-1}\right)$. 2) when the stand age of plantations is 60 years, Pinus densiflora plantation $\left(64.02 \pm 11.06 \mathrm{~g} \cdot \mathrm{kg}^{-1}\right)>$ Quercus variabilis plantation $\left(46.6 \pm 11.48 \mathrm{~g} \cdot \mathrm{kg}^{-1}\right)>$ Pinus thunbergii plantations $(29.20 \pm$ $\left.4.95 \mathrm{~g} \cdot \mathrm{kg}^{-1}\right)$. And Pinus densiflora plantation was significantly higher than the other two types of plantations in terms of the organic matter content (Fig. 1A).

In plantations with the same forest type but different stand age, the organic matter content of the surface soil was as follows: three plantations with 60 years of stand age had more organic matters than those with 30 years of stand age, where the Pinus densiflora plantation with 60 years of stand age is significantly higher than that with 30 years of stand age in terms of the organic matter content (Fig. 1A).

\section{Active organic carbon of surface soil}

In plantations with the same stand age but different forest types, the content of active organic carbon of surface soil was as follows: 1) when the stand age of plantations is 30 years, Quercus variabilis plantation $\left(22.80 \pm 1.87 \mathrm{~g} \cdot \mathrm{kg}^{-1}\right)>$ Pinus thunbergii plantation $\left(14.21 \pm 2.22 \mathrm{~g} \cdot \mathrm{kg}^{-1}\right)>$ Pinus densiflora plantation $\left(12.06 \pm 3.66 \mathrm{~g} \cdot \mathrm{kg}^{-1}\right)$, where Quercus variabilis plantation was significantly higher than the other two types of plantations in terms of the content of active organic carbon. 2) When the stand age of plantations is 60 years, Pinus thunbergii plantation $\left(20.39 \pm 0.34 \mathrm{~g} \cdot \mathrm{kg}^{-1}\right)>$ Quercus variabilis plantation $\left(20.30 \pm 0.41 \mathrm{~g} \cdot \mathrm{kg}^{-1}\right)>$ Pinus densiflora plantation $(19.87 \pm$ $\left.0.34 \mathrm{~g} \cdot \mathrm{kg}^{-1}\right)($ Fig. 1B).

In plantations with the same forest type but different stand age, the content of active organic carbon of surface soil was as follows: 1) the group of Pinus thunbergii plantation and Pinus densiflora plantation with 60 years of stand age were higher than the group with 30 years of stand age, while the Quercus variabilis plantation group with 60 years of stand age was lower than the group with 30 years of stand age in terms of the active organic carbon content (Fig. 1B).

\section{Total nitrogen of surface soil}

In plantations with the same stand age but different forest types, the content of total nitrogen of surface soil was as follows: 1 ) When the stand age of plantations is 30 years, Pinus thunbergii plantation $\left(1.54 \pm 0.44 \mathrm{~g} \cdot \mathrm{kg}^{-1}\right)>$ Quercus variabilis plantation $(1.43 \pm$ $\left.0.37 \mathrm{~g} \cdot \mathrm{kg}^{-1}\right)>$ Pinus densiflora plantation $\left.\left(1.14 \pm 0.32 \mathrm{~g} \cdot \mathrm{kg}^{-1}\right) .2\right)$ When the stand age of plantations is 30 years, Pinus densiflora plantation $\left(2.56 \pm 0.50 \mathrm{~g} \cdot \mathrm{kg}^{-1}\right)>$ Quercus variabilis plantation $\left(1.65 \pm 0.34 \mathrm{~g} \cdot \mathrm{kg}^{-1}\right)>$ Pinus thunbergii plantation $\left(1.22 \pm 0.23 \mathrm{~g} \cdot \mathrm{kg}^{-}\right.$ ${ }^{1}$ ), where Pinus densiflora plantation was significantly higher than the other two types of plantations in terms of the total nitrogen content of surface soil (Fig. 1C). 
In plantations with the same forest type but different stand age, the total nitrogen content of surface soil was as follows: the Pinus densiflora plantation group with 60 years of stand age was significantly higher than the group with 30 years of stand age in terms of the total nitrogen content, but the Pinus thunbergii plantation group with 60 years of stand age was lower than the group with 30 years of stand age. Contrarily, the Quercus variabilis plantation group with 60 years of stand age was higher than the group with 30 years of stand age in terms of the total nitrogen content of surface soil.


Figure 1. Content difference of soil organic matter (SAM, A), soil active organic carbon (SAC, $B)$, soil total nitrogen (STN, C), soil available phosphorus $(S A P, D)$ and soil available potassium (SAK, E) of Pinus thunbergii plantation, Pinus densiflora plantation and Quercus variabilis plantation in 30 years of age and 60 years of age in Mount Meng (average + standard error). $\square 30$ years of age; 60 years of age

\section{Available phosphorus of surface soil}

In plantations with the same stand age but different forest types, the available phosphorus content of surface soil was as follows: 1) When the stand age of plantation is 30 years, Quercus variabilis plantation $\left(18.43 \pm 3.85 \mathrm{mg} \cdot \mathrm{kg}^{-1}\right)>$ Pinus thunbergii plantation $\left(17.85 \pm 3.15 \mathrm{mg} \cdot \mathrm{kg}^{-1}\right)>$ Pinus densiflora plantation $\left(17.64 \pm 2.38 \mathrm{mg} \cdot \mathrm{kg}^{-1}\right)$. 2) When the stand age of plantation is 60 years, Quercus variabilis plantation $(21.65 \pm$ $\left.0.18 \mathrm{mg} \cdot \mathrm{kg}^{-1}\right)>$ Pinus densiflora plantation $\left(19.74 \pm 0.21 \mathrm{mg} \cdot \mathrm{kg}^{-1}\right)>$ Pinus thunbergii plantation $\left(19.55 \pm 0.26 \mathrm{mg} \cdot \mathrm{kg}^{-1}\right)($ Fig. 1D). 
In plantations with the same forest type but different stand age, the available phosphorus content of surface soil was as follows: 1) The three types of plantations with 60 years of stand age were higher than those with 30 years of stand age in terms of the available phosphorus content of surface soil, where the Pinus densiflora plantation group with 60 years of stand age had significantly more available phosphorus than the group with 30 years of stand age (Fig. 1D).

\section{Rapidly available potassium of surface soil}

In plantations with the same stand age but different forest types, the rapidly available potassium content of surface soil was as follows: 1) When the stand age of plantation is 30 years, Quercus variabilis plantation (42.20 $\left.\pm 2.86 \mathrm{mg} \cdot \mathrm{kg}^{-1}\right)>$ Pinus thunbergii plantation $\left(40.53 \pm 3.93 \mathrm{mg} \cdot \mathrm{kg}^{-1}\right)>$ Pinus densiflora plantation $\left(45.37 \pm 2.77 \mathrm{mg} \cdot \mathrm{kg}^{-1}\right)$. 2) When the stand age of plantation is 60 years, Pinus densiflora plantation $(45.37 \pm$ $\left.2.77 \mathrm{mg} \cdot \mathrm{kg}^{-1}\right)>$ Quercus variabilis plantation $\left(40.09 \pm 2.64 \mathrm{mg} \cdot \mathrm{kg}^{-1}\right)>$ Pinus thunbergii plantation $\left(38.43 \pm 3.15 \mathrm{mg} \cdot \mathrm{kg}^{-1}\right)$ (Fig. 1E).

In plantations with the same forest type but different stand age, the rapidly available potassium content of surface soil was as follows: 1) in terms of the rapidly available potassium content, the Pinus densiflora plantation group with 60 years of stand age was higher than the group with 30 years of stand age, while the other two types of plantations with 60 years of stand age were lower than those with 30 years of stand age (Fig. 1E).

\section{Principal component analysis of soil nutrients}

The accumulative variance contribution rates of the first and second principal components respectively reached $81.05 \%$ and $80.81 \%$ in Mount Meng's plantations with 30 years and 60 years of stand age as shown in Tables 1 and 2, which revealed the majority of information. In Mount Meng's plantations with 30 years and 60 years of stand age, the first principal component was closely relevant to organic matters, total nitrogen, available phosphorus and rapidly available potassium, with the accumulative variance contribution rates being $59.85 \%$ and $59.05 \%$ as shown in Table 1 and Figure 2A. In Mount Meng's plantations with 30 years and 60 years of stand age, the second principal component was closely relevant to the active organic carbon of the soil with the accumulative variance contribution rates being $21.20 \%$ and $21.76 \%$ as shown in Table 2 and Figure $2 B$.

Table 1. Soil nutrients of 30a plantation in principal component analysis in Mount Meng, China

\begin{tabular}{l|c|c|c|c|c}
\hline & SAM & SAC & STN & SAP & SAK \\
\hline Main component 1 & 0.95 & -0.11 & 0.91 & 0.88 & 0.70 \\
\hline Main component 2 & 0.05 & 0.98 & -0.09 & 0.28 & -0.15 \\
\hline
\end{tabular}

The total explanatory power of two principal components was $81.05 \%$, where principal component 1 and principal component 2 were $59.85 \%$ and $21.20 \%$, respectively

SAM: soil organic matter; SAC: soil active organic carbon; STN: soil total nitrogen; SAP: soil available phosphorus; SAK: soil available potassium 
Table 2. Soil nutrients of 60a plantation in principal component analysis in Mount Meng, China

\begin{tabular}{l|c|c|c|c|c}
\hline & SAM & SAC & STN & SAP & SAK \\
\hline Main component 1 & 0.94 & 0.09 & 0.89 & 0.91 & 0.67 \\
\hline Main component 2 & 0.19 & 0.96 & 0.12 & -0.27 & -0.18 \\
\hline
\end{tabular}

The total explanatory power of two principal components was $80.81 \%$, where principal component 1 and principal component 2 were $59.05 \%$ and $21.76 \%$, respectively

SAM: soil organic matter; SAC: soil active organic carbon; STN: soil total nitrogen; SAP: soil available phosphorus; SAK: soil available potassium

\section{Discussion}

The differences of the surface soil nutrients in the forest are largely influenced by the types of vegetation. They are mainly reflected like this: plant litters and root exudates keep supplementing the surface soil nutrients and energy substances (Hedwall et al., 2015; Jia et al., 2005). Litter is an important structure and functional unit of material circulation and energy flow in the forest ecosystem (Jia et al., 2016). As the folia of needle-leaved trees have more lignin content (Wang et al., 2009) and relatively less leaf area than broad-leaved trees (Wang et al., 2004; Guo et al., 2006), the litter decomposition rate gets limited, thus influencing the nutrient return rate of litters. Some research shows that: when the stand age is the same, the soil of broad-leaved threes has more nitrogen than that of needle-leaved trees. It is thought that a large quantity of deciduous input and quicker litter decomposition rates could be used to explain why broadleaved trees are higher than needle leaved trees in terms of the topsoil fertility in the broadleaved deciduous forest (Jiang and $\mathrm{Xu}, 2006$; Laganière et al., 2010). We suggest that for plantations with similar environmental backgrounds, Pinus densiflora are more suitable than Pinus thunbergii and Quercus variabilis in terms of maintaining soil nutrients when selecting tool species.

\section{Conclusion}

The research found that: when the stand age is 60 years, the content of organic matters, total nitrogen and rapidly available potassium was presented in a descending order: Pinus densiflora plantation>Quercus variabilis plantation>Pinus thunbergii plantation, and the content of active organic carbon was as follows: Quercus variabilis plantation>Pinus densiflora plantation>Pinus thunbergii plantation. The content of available phosphorus was as follows: Quercus variabilis plantation>Pinus densiflora plantation> Pinus thunbergii plantation. The research result relevant to Pinus densiflora plantation and Quercus variabilis plantation supported the first research hypothesis.

When the stand age of Pinus densiflora plantation changes from 30 years to 60 years, the content of surface soil nutrients all increased, including organic matters, active organic carbon, total nitrogen, available phosphorus and rapidly available potassium, where the content of organic matters, active organic carbon, total nitrogen, available phosphorus significantly increased. The research result relevant to Pinus densiflora plantation basically supported the second research hypothesis. 
Acknowledgements. Funded by the National Natural Science Foundation of China, NO. 41401329 and Fund of Shandong Provincial Key Laboratory of Water and Soil Conservation and Environmental Protection, Linyi University, NO. STKF201603.

\section{REFERENCES}

[1] Bai, F., Sang, W. G., Li, G. Q., Liu, R. G., Chen, L. Z., Wang, K. (2008): Long-term protection effects of national reserve to forest vegetation in 4 decades: biodiversity change analysis of major forest types in Changbai Mountain Nature Reserve, China. Science in China Series C: Life Sciences 51: 948-958.

[2] Gao, Y., Ci, H. X., Qiu, Z. L., Chen, Y. F. (2009): Plant diversity and its elevational gradient patterns in Mengshan Mountain, Shandong, China. - Acta Ecologica Sinica 29: 6377-6384 (in Chinese).

[3] Gao, Y., Chen, Y. F., Dong, H., Hao, J. C., Ci, H. X. (2011): Vegetation and species diversity change analysis in 50 years in Tashan Mountain, Shandong Province, China. Acta Ecologica Sinica 31: 5984-5991 (in Chinese).

[4] Gao, Y., Zhu, K, S., Hao, J. C., Xu, L. S. (2013): An evaluation of the afforestation outcome of six tree species in more than 40 years in Mengshan mountain, Shandong province, China. - Chinese Journal of Plant Ecology 37: 728-738 (in Chinese).

[5] Guo, Z. L., Zheng, J. P., Ma, Y. D., Li, Q. K., Yu, G. R., Han, S. J., Fan, C. N., Liu, W. D. (2006): Researches on litterfall decomposition rates and model simulating of main species in various forest vegetations of Changbai Mountains, China. - Acta Ecologica Sinica 26: 1037-1046 (in Chinese).

[6] Hedwall, P. O., Skoglund, J., Linder, S. (2015): Interactions with successional stage and nutrient status determines the life-form-specific effects of increased soil temperature on boreal forest floor vegetation. - Ecology and Evolution 5: 948-960.

[7] Jia, B. R., Zhou, G. S., Liu, Y. Z., Jiang, Y. L. (2016): Spatial pattern and environmental controls of annual litterfall production in natural forest ecosystems in China. - Scientia Sinica Vitae 46: 1304-1311 (in Chinese).

[8] Jia, G. M., Cao, J., Wang, C. Y., Wang, G. (2005): Microbial biomass and nutrients in soil at the different stages of secondary forest succession in Ziwulin, northwest China. Forest Ecology and Management 217: 117-125.

[9] Jiang, P. K., Xu, Q. F. (2006): Abundance and dynamics of soil labile carbon pools under different types of forest vegetation. - Pedosphere 16: 505-511.

[10] Laganière, J., Angers, D., Paré, D. (2010): Carbon accumulation in agricultural soils after afforestation: a meta-analysis. - Global Change Biology 16: 439-453.

[11] Li, D. J., Niu, S. L., Luo, Y. Q. (2012): Global patterns of the dynamics of soil carbon and nitrogen stocks following afforestation: a meta-analysis. - New Phytologist 195: 172181.

[12] Nave, L. E., Swanston, C. W., Mishra, U., Nadelhoffer, K. J. (2013): Afforestation effects on soil carbon storage in the United States: a synthesis. - Soil Science Society of America Journal 77: 1035-1047.

[13] Nilsson, M. C., Wardle, D. A. (2005): Understory vegetation as a forest ecosystem driver: Evidence from the northern Swedish boreal forest. - Frontiers in Ecology and the Environment 3: 421-428.

[14] Roy, P. K., Samal, N. R., Roy, M. B., Mazumdar, A. (2010): Soil carbon and nutrient accumulation under forest plantations in Jharkhand State of India. - Clean-Soil Air Water 38: 706-712.

[15] Rutigliano, F. A., Ascoli, R. D., De Santo, A. V. (2004): Soil microbial metabolism and nutrient status in a Mediterranean area as affected by plant cover. - Soil Biology and Biochemistry 36: 1719-1729. 
[16] Schmidt, M., Veldkamp, E., Corre, M. D. (2015): Tree species diversity effects on productivity, soil nutrient availability and nutrient response efficiency in a temperate deciduous forest. - Forest Ecology and Management 338: 114-123.

[17] Togonidze, N., Akhalkatsi, M. (2015): Variability of plant species diversity during the natural restoration of the subalpine birch forest in the Central Great Caucasus. - Turkish Journal of Botany 39: 458-471.

[18] Trumbore, S. E., Czimczik, C. I. (2008): An uncertain future for soil carbon. - Science 321: 1455-1456.

[19] Vesterdal, L., Schmidt, I. K., Callesen, I., Nilsson, L. O., Gundersen, Per. (2008): Carbon and nitrogen in forest floor and mineral soil under six common European tree species. Forest Ecology and Management 255: 35-48.

[20] Wang, F. M., Zhu, W. X., Chen, H. (2016): Changes of soil C stocks and stability after 70-year afforestation in the northeast USA. - Plant and Soil 401: 319-329.

[21] Wang, H., Chen, L., Song, M., Song, T. Q., Zeng, Y. P., Peng, X. X., Du, H., Su, L. (2017): Spatial heterogeneity of soil phosphorus and potassium in a mixed evergreen and deciduous broad-leaved forest in karst region of southwest China. - Acta Ecologica Sinica 37: 8285-8293 (in Chinese).

[22] Wang, X. E., Xue, L., Xie, T. F. (2009): A review on litter decomposition. - Chinese Journal of Soil Science 40: 1473-1478 (in Chinese).

[23] Wang, X. H., Huang, J. J., Yan, E. R. (2004): Leaf litter decomposition of commen trees in Tiantongwang. - Chinese Journal of Plant Ecology 28: 457-467 (in Chinese).

[24] Wei, J. J., Gao, Y., Zhao, W. G., Liu, J. (2017): Hillside topographic pattern of shrub and herb diversity of forest in Mount Tai of China. - Journal of Environmental Protection and Ecology 18: 571-580.

[25] Xu, Z. H., Ward, S., Chen, C. R., Blumfield, T., Prasolova, N., Liu, J. X. (2008): Soil carbon and nutrient pools, microbial properties and gross nitrogen transformations in adjacent natural forest and hoop pine plantations of subtropical Australia. - Journal of Soils and Sediments 8(2): 99-105.

[26] Yin, W. D., Gao, Y., Liu, J., Zhao, W. G. (2018): Influence of scenic road corridor to plant diversity in Kunyu Mountain, China. - Applied Ecology and Environmental Research 16: 1461-1469. 